\title{
The Influence of Steel Connection on Fire Resistance of Composite Steel-Framed Buildings
}

\author{
Mohammed Kadhim', Zhaohui Huang ${ }^{2}$ \\ Brunel University London/ UK ${ }^{1,2}$
}

\begin{abstract}
Steel connections play a significant part in enhancing the robustness of structures in the event of a fire. Therefore, it is important to examine the impact of steel connections on the fire resistance of composite steel framed buildings. In this paper, both the behaviour of steel connections and their effect on composite steel frames are analysed using the non-linear finite element computer software VULCAN at various temperatures. The chosen frame is subjected to ISO834 fire. A comparison between end plate connections, pinned connection and rigid connection has been carried out. By applying different compartment fires, some cases are studied to show the behaviour of steel connection when the fire is applied at certain beams. From the analytical results, it was found that the beam with extended end plate is stronger and has better performance in terms of axial forces than those beams with flush end-plate connection. Furthermore, that extended end plate connection has highest limiting temperatures compared to the flush end plate connection. In addition, it was observed that the performance of end-plate connections is very close to rigid connection and very far from pinned connections. The article will conclude that the behaviour of composite steel framed buildings is largely dependent on the steel connection due to their high impact under fire condition. It is recommended to consider the extended end-plate in the design proposals because of its higher fire resistant properties compared to the flush end-plate connection. Finally, this paper shows that steel connection has an important effect on the fire resistance of composite steel framed buildings.
\end{abstract}

Keywords: End-plate connections; fire resistance; finite element modelling; connection behaviour; composite steel-framed buildings. 